\title{
How ethical leadership is related to authenticity
}

\author{
Florian Demont-Biaggi ${ }^{1}$ (1)
}

Received: 2 May 2019 / Accepted: 25 January 2020 / Published online: 13 February 2020

(c) The Author(s) 2020

\begin{abstract}
In this conceptual paper, I shall explain one concrete way of defining ethical leadership, namely authentic leadership. After a description of the ethical components some canonical proponents envisage, objections from the recent literature will be discussed. The main focus will be on how the concept of authenticity helps us to better understand ethical leadership. The central line of thought is this: If we construe authenticity in interactional and processual terms, where leadership is seen as a process of interaction between people in concrete contexts, then we may identify patterns of leadership development through which we can make sense of how authenticity and ethics are related. In the end, as will be argued, these patterns have one pivot: authenticity and ethics come together in a leader's moral conscience. But moral conscience also has important implications on the level of interactions between people in groups and thus affect how ethical leadership influences followers and organizational structures. It is this last thought, which will conclude the article.
\end{abstract}

Keywords Leadership ethics $\cdot$ Authentic leadership $\cdot$ Philosophy of leadership $\cdot$ Moral conscience

\section{Introduction}

According to Peter Drucker, managers-a term he often construes broadly enough to encompass all sorts of leadershipmust achieve results. That is the rationale behind their power over others and their very existence. And when it comes to ethical concerns, he advocates a minimalistic approach ${ }^{1}$ : while pursuing their objectives, leaders should do no harm. ${ }^{2} \mathrm{He}$ does, however, caution that proper application of this simple principle is more challenging that one might expect.

Just how much more challenging it is for leaders to do no harm is not something that only recently has become clear: that the temptations of power are the greatest ethical challenge for leaders is an insight, the implications of which have exercised leadership scholars at least since Plato's Republic (Ciulla 2017, p. 460; Plato 1992). Nevertheless, empirical research on power and what effects power has on leaders helps us elucidate what sort of challenge we are dealing with. Van Kleef et al. (2008) found that because of power, leaders were less compassionate and felt less distressed when others were distressed. According to Blader and Chen (2012), power seems to diminish justice towards others. And

Florian Demont-Biaggi

florian.demont@milak.ethz.ch

1 MILAK At ETH Zurich, 8903 Birmensdorf, Switzerland there is evidence that powerholders are more self-concerned and tend to prioritize themselves over others, while finding themselves also more inspiring (van Kleef et al. 2015). It also seems that leaders with much power tend to violate social norms more frequently (Galinsky et al. 2008) and engage more often in risk-seeking behavior (Anderson and Galinsky 2006). On the other hand, power may raise moral awareness, decrease self-interest over time and enhance altruistic behavior if leaders have a strong moral identity and a prosocial attitude (DeCelles et al. 2012; Chen et al., 2001). If we therefore want leaders who follow Drucker's ethical principle, we need to spell out clearly what leaders should and should not do in order to not harm-and traditionally this has been the purview of ethics. And since, as Ciulla (2017, p. 439) notes, in leadership we see both ethical

\footnotetext{
${ }^{1}$ In what follows, a clear distinction between ethics and morality is not necessary to follow the argument. But as I do employ both terms, I should probably say something about how I use them. "Morality" and anything "moral" refers to rules and prescriptions guiding thought and action in a way that makes them right or good. Morality is a convention individuals adopt for themselves or a convention of groups. "Ethics" and anything "ethical" is concerned with the big issues: what makes a good life? Or, what is goodness per se? Ethics may, on some construal, collapse into morality. But if there is anything good or right over and above habits of individuals or conventions of groups, the study of it will fall into the domain of ethics and not morality.

2 Drucker 2008, p. 220-224.
} 
and unethical behavior magnified, the study of ethics is fundamental to the study of leadership.

A complete discussion of the ethics at the heart of leadership is not something than can be delivered in one paper and I shall concentrate thus on a particular aspect. Among the various ways that leadership ethics has been approached, some simply apply general ethical principles to leadership cases, while a few others actually put ethical concerns at the center of a leadership account. ${ }^{3}$ Given the effects power has on people and given the fact that there is no leadership without some exercise of power, the findings cited above suggest that approaches putting ethical concerns at the center of leadership will have more explanatory power (and possibly more practical relevance). Ethics traditionally belongs to philosophy and much cutting-edge research in leadership studies is based on methods and theories of psychology (and other social sciences). Furthermore, much valid work on leadership ethics is rooted in the humanities. All this of course raises a question about how to best approach the ethical concerns at the center of leadership. ${ }^{4}$ And in order to have any prospect of real progress, we should beware of pitting one against the other right from the start.

Since, neither psychological research nor research in the humanities can begin without at least a preliminary idea of the object to be studied, conceptual issues enjoy first priority. This is therefore a paper in applied philosophy employing conceptual analysis as its main method. Such an approach has to be distinguished from the sort of theoretical paper geared at empirical research, one which mainly seeks to establish operationalizations of certain concepts and research questions answerable by particular empirical methods and models-methods and models, the choice of which is often predetermined through the author's area of expertise, parochial research trends, or conventions within a particular domain of research. We cannot simply presume that some method or model (together with particular operationalization conditions for concepts) is preferable to others. It is therefore necessary to begin with philosophical analyses on the topic of ethical leadership, despite the fact that philosophical papers do not per se make empirical contributions. Philosophical analyses do prepare the grounds for empirical endeavors by elucidating the relevant concepts and sometimes they also draw attention to the danger of simplifying certain concepts too much if an operationalization of concepts for empirical research is pressed for too early.

\footnotetext{
${ }^{3}$ Ciulla and Forsyth 2011, p 239.

${ }^{4}$ Ciulla (2017, pp 339-440) argues that some of the most interesting insights on leadership and ethics can be found in ancient texts from the East and West. One of the most important benefits of a humanities approach studying these texts is that it does not allow a study of leader effectiveness without at the same time examining leadership ethics.
}

Of course, philosophy drawing on and spelling out common sense exclusively is much less useful than philosophy that also draws on actual practice and evidence. But where do we get relevant practical insights and evidence with which to begin a study of ethical leadership? In this paper, I shall discuss a proposal that has enjoyed much popularity between 2003 and 2013, but seems to have drawn much less interest in recent years. Bill George's book Authentic Leadership. Rediscovering the Secrets to Creating Values (George 2003) presented a practitioner's account of how authenticity - that is, knowledge and adherence to one's inner values-is the basis of a form of leadership that is both ethically good and efficient. At about the same time Luthans and Avolio (2003) introduced a leadership theory heavily inspired by positive psychology, which also claimed that knowledge of and adherence to inner values were the marks of leaders who are both ethical and efficient. So, there, back in 2003, a practitioner and two academic researchers claimed that the notion of authenticity - if suitably construed - lies at the heart of ethical leadership, precisely in the sense that we are looking for here.

Unfortunately, neither strand did articulate in detail how authenticity and good leadership (i.e. one which is both ethical and efficient) do hang together. In fact, the terms "authentic leadership" and "authenticity" have been absent from the title of their publications in the last few years. In 2014 Avolio and Walumbwa admitted concerning the ethical component of their theory (p. 345):

Clearly, a lot of work remains to determine under what conditions authentic leadership may be more or less

likely to foster ethical outcomes.

This reflects the now dominant view that the authentic leadership approach has not succeeded in articulating convincingly how authenticity and ethical leadership are related. ${ }^{5}$ The aim of this paper is to show that not all is lost. There is indeed a way of reading basic tenets of authentic leadership theory that establishes a clear connection between authenticity and ethical leadership. The missing link, as I shall argue, is a conception of moral conscience, which is basically nothing else than an awareness of one's ethical values. Ethical leadership does, however, not stop with the individual leader but also encompasses followers and organizational structures (together with their corresponding social conventions). If authenticity is indeed relevant for ethical leadership, it must hence elucidate the social dimension of ethical leadership as well. I shall therefore explain also to

\footnotetext{
5 Standard undergraduate textbooks (e.g. Northouse 2016), critical reviews in standard reference works (e.g. Caza and Jackson 2011) and contributions by major researchers in the field (e.g. Avolio and Walumbwa 2014) are unanimous on this point.
} 
what extent the conception of moral conscience might clarify the social dimension of ethical leadership, thus rounding off the discussion.

In order to argue for the claim that authentic leadership theory still has something important to teach us about ethical leadership, I shall discuss four issues in subsequent order. First, a presentation of the basic tenets of authentic leadership together with an interpretation of what role ethics plays in it will be provided. In some respects my presentation will be sympathetic to canonical authors and in other respects I shall criticize them, in particular when they are inconsistent, where bolder claims would be sensible or where they claim more than they can prove. In a second section, I shall address the issue of how the account of ethical leadership carved out in the first section envisages an implementation of ethics in leadership practice. The main aim of the section is to provide reasons for the claim that the account is practically relevant. In a third section, having established the basic structure of the account together with its practical implications, I turn to some of the criticisms of authentic leadership theory, which have raised objections to its ethical component. The fourth and last section will address the social dimension of ethical leadership. How does the ethical component of authentic leadership affect followers and organizational structures? I shall claim that the account to be defended here implies social conventions, which establish a normative structure governing social interactions in organizations. This social dimension is an integral aspect of the relation between authenticity and ethical leadership.

\section{Ethics in Authentic leadership theory}

There are numerous publications addressing authentic leadership. But if we want an account to make sense of how authenticity and ethics go together, while paying special attention to individual leaders' personalities and the particular development of authentic leaders, the work of Bruce Avolio and his colleagues is a sensible starting point. ${ }^{6}$ In what follows, "authentic leadership theory" and related expressions refer to this account.

The account is best understood as combining certain strands of research on transformational leadership and others on positive organizational behavior (Luthans and Avolio 2003). According to this view on authentic leadership, a processual point of view makes sense: authentic leaders have a particular biography, as they are willing and able to face and deal with difficult situations, which eventually makes them

\footnotetext{
${ }^{6}$ Luthans \& Avolio 2003; Avolio \& Gardner, 2005; Gardner, Avolio \& Walumbwa, 2005; Walumbwa, Avolio, Gardner, Wernsing \& Peterson, 2008 .
}

become authentic. ${ }^{7}$ Such a focus has also been proposed by practitioners (George 2003) and scholars often see this as a matter of personality, which can be measured (Avolio and Gardner 2005).

Leadership development thus forms the primary topic for this take on authentic leadership. Apart from trying to integrate positive psychology models including hope, efficacy, resiliency and optimism, results about positive organizational behavior, transformational/full-range leadership and ethical and moral perspective-taking are the new ingredients Luthans and Avolio (2003) sought to bring into authentic leadership development research (and its practice).

For present purposes, the account of ethical and moral perspective-taking (Schulman 2002) and its integration in authentic leadership theory as proposed by May et al. (2003) will provide the footing for clarifying the role ethics plays in authentic leadership theory. Usually, these are the sources cited as providing the roots and context for understanding the ethical aspects of authentic leadership theory. ${ }^{89}$

Michael Schulman's "How We Become Moral" (2002) is not a philosophical account of ethics, but-first and foremost-an account in moral psychology focused on moral motivation and its development. ${ }^{10}$ Nevertheless, he frequently adduces evidence for the philosophically relevant claim that humans possess an intrinsic sensitivity to harming and helping (2002, p. 503), which he also calls "care about goodness". He concludes his article with the following passage (2002, pp. 509-510):

\footnotetext{
${ }^{7}$ Earlier landmarks regarding this particular line of research were Bennis \& Thomas 2002 and Shamir \& Eilam 2005.

${ }^{8}$ See, for example, Avolio \& Gardner 2005, p. 332 and Gardner, Avolio, Luthans et al. 2005a, b, p. 345.

${ }^{9}$ One might wonder whether a paper from 2003 is a bit dated. While May et al. 2003 has been cited 831 times (according to Google Scholar November 2019), I have not found one publication that does not simply draw on that paper, but offers a critical discussion of the various points it raises. Something similar can be said regarding Schulman's 2002 article. The only difference is that the latter has been cited considerably less frequently. This of course underlines that there is work to be done regarding the relation of authenticity and ethical leadership.

10 Sometimes moral values or moral judgments are entertained but do not lead to moral actions (which, in turn, do not lead to moral consequences). Investigating moral motivation is an attempt to bridge this gap. An account of moral motivation thus explains how individuals are affected by moral values, moral judgments, moral virtues etc. and thus are moved to act in accord with them and possibly even persist in the face of adverse circumstances. Moral motivations can be based on reasons for action, emotions or unconscious drives (maybe even combinations of these). A full understanding also involves an explanation of how they are developed, since sometimes they are lacking and we would like to know whether, how and to what extent people with good values can become true moral agents.
} 
That extreme goodness feels more normal to us than extreme badness is worth remembering as we, scientists and laypersons, try to piece together an understanding of human nature. Somehow, we have been ushered down a unique evolutionary path where, unlike any other biological system, we have come to care about goodness. This interest in, and responsiveness to, morality has played a major role in the development of human civilization and has contributed enormously to the survival and flourishing of our species.

Such an informed commitment to an anthropological constant is of course highly relevant for the application of ethics to leadership, since it narrows our focus down to a perspective, where we claim (based on empirical research and not merely on armchair philosophy) that moral goodness is primarily about a psychological capacity with both a particular motivation mechanism and a particular development in the background. From a philosophical perspective, we might best call this a naturalistic account of moral conscience. ${ }^{11}$ Hence, when discussing ethics in the context of authentic leadership theory, we are primarily discussing the topic of moral conscience and how that explains the relations between authenticity and ethical leadership.

Here we may already note an important connection to what Drucker tells us about leadership ethics. According to him, leaders should do no harm while pursuing their objectives. If read together with the claim that there is an intrinsic sensitivity to harming and helping, Drucker's take on leadership ethics simply spells out a necessary normative constraint on leadership, which does not obtain because of invention, the historical development of certain cultures or social conventions, but which obtains because of basic evolutionary facts about human nature. ${ }^{1213}$ But how does this psychological capacity affect our deeds, speech acts and moral judgments?

The ability to deal with challenging situations, of which Avolio and his colleagues claimed that it lies at the heart of

\footnotetext{
11 It is an account of moral conscience, because it describes a moral sense of good and bad. And since this moral sense is explained in biological and psychological terms (rather than drawing on a priori or religious notions) it is a naturalistic account.

12 On this point, compare also Greene 2013, pp. 36-9, who gives further details on the human aversion to violence, positive acts of kindness (i.e. care about others) and the neurological basis of empathy (i.e. the emotional reaction to experiences of others, especially suffering, which is a necessary precondition for care about others).

13 Note that Avolio \& Walumbwa (2014, pp. 348-350) explicitly discuss evolutionary aspects of leadership development. It seems probable that they also fully subscribe to Schulman's assumptions about human nature.
}

authentic leadership, can also be found in Schulman's vision of a moral person, of whom he writes (2002, p. 500):

[T]he moral person resists temptation and treats others well out of "internal" motives, doing so even when he or she can get away with doing otherwise.

So, any sensible account of moral motivation must be able to explain this sort of stability. That is a first aspect of the sort of psychological capacity we are after. But there is much more to be said about the psychology of moral conscience.

According to Schulman's proposal, concern for othersthe basic mark he identifies in moral motives-emerges spontaneously in very young children and the morality this gives rise to has, in our species, evolved in three separate forms, which account for significant individual styles of manifesting morality in deeds, speech acts and judgments (2002, p. 500). There are, Schulman continues, three independent sources, which can provide such an explanation: empathy, moral affiliations and principles. But why three and not one? Nature often builds redundancy into vital mechanism to have a backup in case they fail. On this view, the fact that there are three different sources of moral motivation supports the idea that we are actually talking about a vital system, for the existence of which there are good evolutionary reasons. Moral conscience is therefore crucial for survival.

Let us now turn to the details of moral motives. Empathy is the first source of moral motivation and, thus, of human conscience. It is primarily about being motivated to think and behave ethically, because we are moved by people's feelings, especially their suffering. It is the probably normally distributed capacity to imagine ourselves in another's psychological place, to feel their pleasant and unpleasant feelings as if they were our own. Children often begin to manifest empathic reactions by their $18^{\text {th }}$ month (Schulman 2002, p. 501). According to John Gibbs (2013, p. 1) too, social perspective-taking is central to moral development and behavior. It relates to justice, mutual respect as well as caring. Philosopher Derek Parfit (2011, p. 330) wrote that a requirement to imagine ourselves in others' positions is the psychologically most effective way of making us more impartial and of motivating us morally.

This is highly relevant for ethical leadership theory. As was mentioned in the introduction, it is an effect of power that leaders are less compassionate, are less distressed by others' suffering, and also show less justice towards others (van Kleef et al. 2008; Blader and Chen 2012). There is thus evidence that power works against empathy and thus we may infer that it also diminishes moral motivation. But we have also mentioned already that power may raise moral awareness in those leaders who have a strong moral identity and a prosocial attitude (DeCelles et al. 2012; Chen et al. 2001). Based on our present discussion, we can relate this 
to empathy, claiming that power is not always antagonistic to empathy, but may promote it, where it has been developed enough beforehand. In this way, a closer examination of empathy and power explains why power is the source of the biggest ethical challenges for leaders and why building empathy (and possibly more conscious variations of social perspective-taking) is central for developing moral leaders.

So, if empathy is an (or even the) essential property of moral conscience, authenticity-interpreted as, among other things, listening to one's moral conscience-involves a particular sort of mindfulness, one which allows us to relate to another's perspective in order to gain more impartiality and motivation. It is perhaps important to repeat here, that Avolio and his colleagues emphasized that they adopt Schulman's view on perspective-taking for their authentic leadership theory. After all, it has played a very central role in much cutting-edge thinking about the essence of ethics in moral psychology and philosophy. ${ }^{14}$

On a more abstract level, we find moral affiliations (or identification with moral models) as well as commitment to principles or personal standards of right or wrong as further sources of moral motivation. Both involve a concept of goodness: either good models such as a parent, a mentor, a religious figure or even a fictional character, or an abstract standard, ideal, or principle encoding goodness (Schulman 2002, pp. 501-3). Bill George puts special emphasis on this for his practice-oriented vision of authentic leadership when he argues that leaders first have to be clear on their personal moral affiliations, test them under difficult situations and thus set the ethical tone for their organization (2003: 127-8). This is not only prudent leadership, but directly follows from a view about human nature, for Schulman notes that "[o]n their own, children seem to recognize that there should be rules against harming, rules that are not based on authorities" (op. cit., p. 503). Already at age 3, children readily apply the evaluative categories "good" and "bad" to their own actions, which suggests the development of a positive moral identity, according to which they see themselves as moral agents to whom moral criteria can (and should) be applied.

Such principles, standards, moral criteria and especially any notion of goodness presuppose some sort of impartiality. They should be valid, determine what is good and right in a moral sense, for different situations and for different people. However, if impartiality in moral matters requires perspective-taking, we should object to Schulman that his three sources of moral motivation are actually not on a par. Empathy (and anything else perspective-taking does require) is more fundamental for moral conscience and, thus, for

\footnotetext{
${ }^{14}$ For more details on the central role of perspective-taking, the reader should consult Gibbs 2013.
}

authenticity. After all, if listening to one's moral conscience is an essential aspect of authenticity, then authenticity must necessarily require a sensitivity and sufficient motivation to consider other perspectives. This implication for the concept of authenticity is worth stressing, because authenticity qua self-knowledge or self-awareness can much too easily be thought to require some form of introspection. Following the lines of thought just presented, such an approach would be wrong-headed. Instead, it is precisely because of its close ties with moral conscience (and perspective-taking) that self-knowledge is best understood as interactional and not as requiring introspection. Otherwise, why should the knowledge we come to through authenticity be impartial enough for leading other people? It is hard to see what a plausible answer to this question looks like. On the other hand, if authenticity needs be interactional along these lines, an account of ethical leadership based on authenticity will put a special emphasis on the social dimension of ethics and spell out the relevance of ethical leadership for followers and organizational structures. I shall elaborate this insight towards the end of this paper. For now we still have some other topics to cover.

Any account of moral conscience, which presumes an intrinsic sensitivity to harming and helping, must explain harmful actions. Schulman himself mentions displacement of responsibility (he writes "yielding moral responsibility to others") and thinking of others as inherently undesirable as important reasons for moral disengagement - the phenomenon that people can disengage their conscience in order to cause harm without feeling bad (op. cit., p. 508). The idea is thus that moral conscience can be weakened or even disengaged under conditions where responsibility is displaced or victims are dehumanized and that this explains harmful actions. ${ }^{15}$ Recently Albert Bandura has published a detailed account of the various forms of moral disengagement, the conditions under which they appear and discusses a plethora of examples-many of which are also leadership cases. ${ }^{16}$ This sort of approach is helpful to spell out the circumstances in which powerholders must be particularly careful and what they must be careful about. But the question most relevant here is more fundamental and the empirical description Bandura provides does not explain why a

\footnotetext{
$\overline{15}$ For details on displacement of responsibility and dehumanization see Bandura, pp. 58-62 and pp. 84-89.

${ }^{16}$ Bandura's work on moral disengagement is based on his social cognitive theory of human agency, in which the concept of self-efficacy plays a central role. May, Chan, Hodges \& Avolio (2003, p. 255 and p. 257) also stress the importance of self-efficacy, which they see as the basis of moral courage. It is therefore rather easy to find conceptual interfaces between authentic leadership theory and Bandura's work, a point which Avolio \& Walumbwa (2014, pp. 244-5) also emphasize.
} 
living being possessing an intrinsic sensitivity to harming and helping possibly gives in to a susceptibility to harm if circumstances are right. In other words, we have good evidence for the claim that we are susceptible to do harmful things now and then, but we still do not know why that is possible. Bandura (2016, p. 4) writes:

To be an agent is to extent intentional influence over one's functioning and over the course of events by one's actions. The capacity for self-influence gives meaning to the exercise of morality. If human behavior were controlled solely by external forces, it would be pointless to hold individuals responsible for their behavior.

As we are mainly interested in leadership ethics, we cannot wait until philosophers have finished their endless debates on free will before we can address questions of leadership responsibility. Bandura is of course right that we actually do hold in fact hold individuals - and especially leadersresponsible for their behavior (and sometimes also for their beliefs and attitudes) and that we normally presume that they are capable of influencing themselves, thus being able of making choices of whether to do something harmful or not. Such presumptions are commonsensical and we should build on them if our leadership theories and especially our leadership ethics are to have practical relevance.

There is, however, also one aspect of moral disengagement in Schulman's article, which cannot be found in Bandura's work, but which might nevertheless be a sensible candidate for explaining why we are sometimes susceptible to act harmfully: the suppression of so-called "bad thoughts". In order to maintain their positive self-concepts (stemming from the moral identity they have developed as children), people often mislabel and deny such unwanted thoughts, which leads to serious problems in self-regulation (Schulman 2002, p. 508). To flesh Schulman's suggestion out a bit, we focus on cases where an interaction with other people or events brings up desires, fears or any other emotion or thought, which, according to the moral identity we have constructed for ourselves, should not arise in that situation. There is, then, a difference between our reactions during an interaction and what our ideas about our (moral) self prescribes as an appropriate reaction. Instead of engaging empathy and going with the flow of the interaction (as we did when we were children), we cling to our moral identity and suppress these unwanted emotions and thoughts. This, in turn, can cause us to listen less often or less attentively to our moral conscience, especially to the demands of empathy, since we have built a habit of preferring the prescriptions of our moral identity. In this way, moral conscience becomes muzzled and, hence, the very source of our moral identity and an essential part of our authenticity cannot do the sort of work anymore, which it is meant to do. The result may be harmful actions for which we have good reasons - they are in sync with our moral identity after all-but which go against our moral conscience, which was (at least temporally) stifled. So, individuals possibly develop habits, which manifest as unchecked antisocial impulses, something that is highly undesirable in general and particularly in powerholders. Bill George, writing from a practitioner's point of view, observes (2003, p. 14-15):

Accepting your shadow side is an essential part of being authentic.

The academic literature on authentic leadership (and arguably on ethical leadership in general) tends to ignore this particular form of moral disengagement. ${ }^{17}$ Nevertheless, there is a large literature on the psychodynamic factors of leadership, which describes and explains the phenomenon (Kets de Vries and Balazs 2011). Psychodynamic approaches utilize the concepts of the unconscious and transference to explain our capacity for self-influence in ways that are sensitive to individual characteristics and the history of individual psychological development. In particular, our ways of reacting to power and how these affect our possibilities for exercising intentional influence on our functioning may have unconscious aspects which do not play in a role in Bandura's account. ${ }^{18}$

Merging research on authentic leadership (and ethical leadership in general) with psychodynamic explanations of moral disengagement (and dysfunctional behavior in general) is a promising line of inquiry, precisely because it promises to yield deeper explanations and, thus, more reliable results on what authenticity and moral conscience require by discovering the roots of inauthentic deeds, speech acts and judgment. It thus helps clarifying the relation between authenticity and ethical leadership, while it opens up a vast array of interventional possibility, because psychodynamics has various methods working on people's capacities for self-influence.

Schulman ends his article with recommendations regarding moral development. Immoral behavior, for him, is as much a product of moral motivation deficits as it is a product of unchecked antisocial impulses (2002, p. 509). Children, therefore, need enough empathy, adequate attachment to moral models (including communities with moral standards) and moral principles. They also need clear and convincing messages that they are expected to develop a positive moral identity. According to authentic leadership theory, the implications for leadership development are obvious. Positive psychology, with its focus on the role of positive

\footnotetext{
17 As the quote from Bill George shows, the topic seems to be more obvious for practitioners.

18 For example Ladkin et al. 2016 suggest that C. G. Jung's notion of individuation can help us refine the concept of authentic leadership, because it provides a way of introducing unconscious aspects into leadership theory that accords a role to the developmental and processual insights developed in the literature on authentic leadership.
} 
emotions in the fulfillment of human potential (Seligman and Csikszentmihalyi 2000), is the primary domain of research, which can be applied to organizational theory to improve workplace performance (Luthans 2002). But the problem of unchecked antisocial impulses and the role they play for moral disengagement is still best addressed within the domain of psychodynamics, where there is a focus on the role of past experiences in the development of human character. There is no reason why insights from this other domain should not also inform the theory and practice of leadership and organizational development. The theory of authentic leadership should hence adopt a more encompassing account of leadership ethics, heeding the proposal by Kets de Vries and Balazs (2011, p. 391) ${ }^{19}$ :

One way in which the two currents might be reconciled in future research in organizational behavior is to start with the clinical paradigm, by acknowledging the origins and role played by dysfunctional human behavior, and then building on it by exposing how the tenets of positive organizational psychology can help human beings overcome certain dysfunctional behaviors by moving away from the negative and damaged towards the more positive and constructive world of possibilities and reparation of negative past experiences.

After this review of the moral psychology presupposed in authentic leadership theory, we are now ready to consider, how some of these themes are explicitly applied to leadership by Avolio and colleagues-and also where we have to go back to moral psychology and philosophy in order to obtain a more complete picture.

\section{Ways of implementing ethics in leadership practice}

We now turn to "Developing the Moral Component of Authentic Leadership" (May et al. 2003), which provides detailed explanations of how ethics is integrated in authentic leadership theory. This account focuses on notions adopted from positive organizational psychology and thus mentions resilience in dealing with difficult issues (op. cit., pp. 247-8), humility (p. 249) and optimism (p. 248) as important marks of authentic leaders. There is, however, also a considerable emphasis on the capacity to recognize the moral dimension of a situation, which involves leaders seeing their role as including an ethical responsibility to their stakeholders as well as a sensitivity to ethical issues and past experiences, from which they have learned to best deal with ethical issues (p. 247). Adequate responsiveness to different stakeholder

\footnotetext{
19 Note that "clinical paradigm" refers to the conceptual framework of psychodynamics, which is employed to study leadership.
}

needs obviously requires perspective-taking and together with a willingness to tackle difficult issues (even if there are no clear solutions in sight), these two are declared to be the marks of an authentic leader's moral capacity (p. 248).

A lack of authenticity in leadership is associated with an excessive interest in short-term performance outcomes and a neglect of consideration of what it would take to create sustainable outcomes. Another reason for inauthentic leadership is a failure "to listen to the voices of their most authentic associates" (op. cit., p. 249). Under the assumption that authentic leaders are per definitionem moral leaders, we may infer that these shortcomings are also sources of immoral leadership behavior.

Note that these are both cognitive shortcomings: on the one hand we have an unwillingness (maybe an inability) to consider the requirements of a sustained pursuit of organizational objectives and on the other hand we have an unwillingness (maybe an inability) to identify and listen to reliable associates. Authenticity is thus thought to involve particular cognitive capacities, some of which are tightly connected to moral capacities. Moreover, of course, perspective-taking itself is a complex cognitive and emotional act lying at the heart of moral development and behavior. We should therefore take some of the statements about the role of self-awareness for moral decision-making with a pinch of salt-for example when May, Chan, Hodges and Avolio write (2003, p. 249):

The important message we wish to convey is that leaders must know what is important to them-they must be totally immersed in their core beliefs and values. This constitutes a fundamental sense of self-awareness. Next, leaders must convey those beliefs and values in every possible interaction at every level of the organization. If all leaders act in accord with their core beliefs and values, then what they say is exactly what they mean.

If read literally, these statements are only true if the core beliefs and values of any leader (anytime, anywhere) discovered through self-awareness involve a sincere commitment to a sustainable pursuit of organizational goals, a humility to listen to others and a sincere interest in all stakeholder needs. Immersion in those beliefs and values must also be connected with the cognitive capacities required to put them into action and to generate appropriate results.

The philosophical commitments behind this approach to the moral component of authentic leadership are considerable. It presupposes a consequentialist ethics, for authentic leaders allegedly achieve ethical results over the long term. It also presupposes a sort of moral conscience, which, if we tap into it, commits us to sustainability and a sincere interest in the needs of all sorts of different stakeholders. 
Furthermore, there are particular cognitive capacities associated with moral conscience, which constitute the sort of practical knowledge needed to act right. Already before actual decision-making begins (that is, on the level of recognizing an issue as moral) an authentic leader has to be aware of six different aspects (p. 251):

1. Issues vary in the degree to which they have consequences for others.

2. Issues differ in the probability of whether those consequences will occur.

3. Consequences may happen in the near or distant future.

4. Individuals who are affected vary in their degree of social, cultural, psychological, or physical closeness to the leader.

5. The consequences of a decision may be concentrated on a few individuals or spread out among many stakeholders.

6. Issues vary in the degree of consensus others have regarding what the leader should do.

This list defines a sensitivity to interdependencies between facts at different times and different people (including their needs), which is used to compile a set of weighted alternatives and that, in turn, is used to develop concrete intentions to act (p. 252). Note that core beliefs and ethical values available through self-awareness can only inform the weighting of alternatives and the development of intentions to act (especially the moral motivations behind acts). The sensitivity to interdependencies and the imagination and experience used to develop the alternatives do much more work than selfawareness and it therefore requires stretching the semantics of the term "authentic" if we still want to call the entire thing an authentic decision-making process.

When it comes to the details of what constitutes an authentic leader's moral capacity, there are three elements, which influence the weighting of alternatives and the development of intentions (especially its motivational component). In these three elements, we find a more detailed vision of how the core beliefs and ethical values available through self-awareness do accomplish work in decision-making (p. 252).

The first aspect is perceptions of the leadership role and it is primarily about a leader's moral identity. That identity should involve a responsibility to act morally (a sincere commitment to do the right thing) and in the best interest of all stakeholders.

The second aspect is perspective-taking ability and we have already noted how central it is to moral development and behavior. The authors stress here its function to develop alternatives and, in particular, to assess the consequences of decisions. It helps when dealing with complex, difficult problems and "raises the chances of finding a simple and straightforward solution" (p. 252). Note that whereas perspective-taking is often associated with empathy, providing a way of developing a relation to the emotional dimension an issue might have for others, the authors now focus on this capacity's potential for carving out different perspectives on a moral problem together with their consequences. It hence serves not only as a basis for emotional, but also for intellectual assessments. This is precisely the point Parfit is after, as we have already mentioned, when he writes that a requirement to imagine ourselves in others' positions is the psychologically most effective way of making us more impartial. It is, therefore, through perspective-taking that we can move from a subjective morality (available through self-awareness of our beliefs and values) to intentions and acts, of which we can claim ethical correctness in a more objective sense. In other words, perspective-taking supports moral justification.

The third aspect is leadership experiences with moral dilemmas. We saw that Schulman believed in an intrinsic sensitivity to harming and helping, which is a result of human evolution. Such a commitment to basic human goodness is also something that shines through in some of the claims May, Chan, Hodges \& Avolio make (even though it is nowhere explicitly argued for). Still, nobody is claiming that goodness is hard-wired. Moral disengagement and unchecked antisocial impulses are just as much facts about human morality as is the necessity to actively counter moral motivation deficits in education if we want to develop moral characters that actually deserve the name. In authentic leadership theory, being a theory about development, leaders have to grapple with difficult moral problems in order to develop (and later hone) the psychological capacities necessary to reliably deal with morally demanding situations. Leaders must be ready to learn, be "'open systems,' constantly updating what they have 'in store' to deal with the most difficult moral problems" (p. 252).

Of course, successful authentic leadership development does not happen in a void and we would starkly misrepresent the spirit of Luthans and Avolio's original article (2003) if we focused on individual personality characteristics only. There are organizational factors, which facilitate authentic leadership development. One such factor is the selection process, during which authenticity and moral motivation should be assessed. Then, top management must provide support for development efforts. They do that by acting as role models and by dedicating resources to the development of authenticity. Furthermore, performance metric systems should provide a sound basis for rewarding a longer-term orientation and for morally good action in the face of pressure to do otherwise (p. 257). For that, leadership development programs may play an important role.

In leadership development programs, moral capacities can be trained specifically. There, leaders should be sensitized to 
stakeholder needs and to how their decisions affect them. ${ }^{20}$ Perspective-taking abilities are honed through work on ethical issues, during which they might employ different ethical reasoning models. The authors also envisage discussions of concrete ethical issues with role models. Training can also enhance self-efficacy and resiliency, both of which help leaders to deal successfully with ethically demanding situations (pp. 257-8).

All in all, the article by May, Chan, Hodges and Avolio contains a detailed and explicit account of how ethics in authentic leadership theory is construed. In our discussion, however, we have found that it makes sense to flesh certain details out by going back to Schulman's proposal. Together with some further developments of the lines of research mentioned by Schulman and a more explicit consideration of philosophical commitments, the entire model appears consistent and applicable. We shall now turn to some objections from the literature. Dealing with them allows us to refine the account a bit more and it even allows us to fill a lacuna of authentic leadership theory.

\section{Reply to objections}

Authentic leadership theory has been criticized by leadership scholars and one important line of criticism addresses its claims to promote ethical leadership. Peter Northouse, for example, writes in his textbook (2016, p. 207):

[T] he moral component of authentic leadership is not fully explained. Whereas authentic leadership implies that leaders are motivated by higher-order end values such as justice and community, the way that these values function to influence authentic leadership is not clear. For example, how are a leader's values related to a leader's self-awareness? Or, what is the path or underlying process through which moral values affect other components of authentic leadership? In its present form, authentic leadership does not offer thorough answers to these questions.

Avolio and Walumbwa (2014, p. 345) seem to concur:

In sum, there is a clear rationale and some preliminary evidence to support the proposed links between authentic leadership and behaving more ethically in organizations. Clearly, a lot of work remains to determine under what conditions authentic leadership may be more or less likely to foster ethical outcomes.

This is, however, not the best answer they could give. Northouse seems to expect an account of how some grand

$\overline{20}$ Bill George (2003, pp. 127-8) puts much emphasis this point as well. values such as justice and community can be internalized, such as to make them available to a self-awareness in order to motivate ethical action and affect other, more rational and value-neutral, aspects of authentic leadership behavior. ${ }^{21}$ Such an expectation arguably has a basis in some of the claims Avolio and his colleagues made. Still, it is completely wrongheaded. The best way of construing the ethical component of authentic leadership is, as has been explained above, along the lines of a naturalistic notion of moral conscience.

Moral conscience, being an awareness of subjective moral beliefs and values, can never tap into grand values, such as an objective idea of justice, which presumably has a precisely carved out content. While developing their moral identity, children do construct preliminary notions of justice and goodness together with corresponding rules, principles and moral criteria to assess situations and their own and others' actions. These notions, however, are rather subjective. It is only through the capacity of empathy, exercised in interactions with other people when perspective-taking is actively practiced, that these subjective notions become more impartial and may become the basis for reliably objective claims about what is good and bad. The process may take a long time and require much experience. It is to be expected that difficult ethical decisions are important for the sort of process constitutive of authentic leadership. If uncertainty and risks are high, if there is external pressure to do something else, perspective-taking becomes more difficult; but if aspiring authentic leaders stay true to their moral conscience and fully exercise their empathic and cognitive capacities, there will be development. In fact, and pace Northouse, authentic leadership theory has close at hand a detailed account of how leaders' values and leaders' self-awareness are related. There is also close at hand a detailed account of moral motivation and of how it develops.

A second objection comes from Joanne Ciulla. In an article about whether Nelson Mandela counts as an authentic leader, she writes (Ciulla 2013, p. 154):

Authentic leadership is basically about how a leader's self-knowledge contributes to making him or her an effective and a moral leader. There is an inherent circularity in the notion of morality in this definition. Morality seems to be both the result of being authentic and a quality of authenticity.

Ciulla does not explicitly claim that such a circularity cannot have much explanatory force in general. But towards the end of her article, she writes that it certainly has not enough explanatory force when it comes to assessing concrete leaders like Nelson Mandela. As an alternative to the authentic

\footnotetext{
${ }^{21}$ I leave aside the question to what extent the word "community" can refer to a value in the sense that "justice" or "benevolence" do.
} 
leadership theory developed by Avolio and colleagues, she suggests paying more attention to what philosophers like Sartre and Heidegger have to say about authenticity (p. 170):

[A] construct of authenticity that centers on selfknowledge is too simplistic to explain complex leaders like Mandela. Leadership scholars would benefit from carefully reading the more nuanced philosophic accounts of authenticity in writers such as Sartre and Heidegger.[...] And [...] the assumption that morality is a quality of an authentic leader and the result of being an authentic leader is circular and too simplistic to stand up to real examples in history. Mandela is not a moral leader because he is authentic, nor is he an authentic leader because he is moral.

There is an important point to be gleaned from this criticism. The emphasis that Avolio and colleagues sometimes put on how self-knowledge and ethical leadership hang together can be misleading. We have to insist that the ethical component of authentic leadership is all about moral conscience. And since moral conscience (itself a conglomerate of psychological capacities) is subject to development as explained above, there is no circularity. People have a moral conscience and by exercising it, they can judge, speak and behave morally. Self-knowledge, drawing on their moral identity (which has developed over time) allows authentic leaders to be ethical leaders.

But, and here Ciulla goes wrong, we must clearly distinguish between possessing a capacity (or a set of capacities, such as that constituting moral conscience) and its exercise. Having two legs does not mean that one can walk. Human infants have to learn it and get better over time. Professional athletes will have to hone this skill more than anybody else in order to deliver outstanding performances. The same is true for moral conscience. Any mentally healthy human being has it and does develop it to some extent. But leaders who hold power and who have to make far-reaching decisions (possibly under pressure and under conditions of risk and uncertainty) will have to hone it much more to deliver the outstanding performances they are expected to deliver.

What may appear as a facile circularity is actually a shorthand expression of the fact that the sort of moral conscience involved in authentic leadership theory must be understood in processual terms. We have to consider moral development and the role of crucibles to understand authenticity clearly. And once we do so, we find that the process authentic leaders go through when honing their ethical decision-making is a dialectical process, one which is by no means lacking complexity. If we consider all elements mentioned above, the resulting account is probably not less nuanced than what Sartre and Heidegger have to say about authenticity. Because its outlook is naturalistic and its claims are subject to empirical research, it might even be clearer and more practically relevant.
Let us now turn to a third objection, one which is explicitly Heideggerian in its approach. What if authenticity has nothing to do at all with ethical values? Algera and LipsWiersma (2012) compared the account of authenticity in authentic leadership theory with the account of authenticity as used in existential theory. Their insightful article contains a variety of important claims, but for present purposes we just focus on one: authenticity is not intrinsically ethical. They write (2012, p. 125):

From an existentialist perspective, the concept of authenticity does not necessarily have ethical implications (Guignon and Pereboom 1995). Even though the ideal of authenticity calls on the individual to live a more focused life that integrates her deeper beliefs, values and concerns in a unified whole, "there is no reason to believe that a person who is authentic necessarily will be a more benevolent or more principled person" ( $p$. xxxiv). Similarly, authenticity might not have any moral implications for the nature of the objective or purpose the individual strives for. What is true or good from the perspective of the authentic individual might not be in line with what is considered as ethical or moral by another human being or by society. [...] In addition, even if the authentic leader has high moral standard[s], making ethical decisions will be challenged by external pressures, like those of the market. Current AL [authentic leadership theory] also fails to address the implications of the profit demands of the market place on the capacity of the leader to act morally or ethically.

The existential concept of authenticity, which Algera and Lips-Wiersma contrast with authentic leadership theory, is borrowed to a large degree from Martin Heidegger. They argue that through this approach, they arrive at a notion of authenticity that is more powerful than what Avolio and his colleagues offer, because the existential analysis recognizes authenticity as a complex and multileveled concept deeply rooted in the ontology of being human. From that perspective, they hold, there is no necessary connection between authenticity and ethics. ${ }^{22}$ But why should authentic leadership theory adopt such an existential perspective?

As we have argued, especially in the discussion of Schulman's moral psychology, the naturalistic conception of moral conscience behind authentic leadership theory does indeed include explicit claims about human nature and uses them as a footing for explaining the psychological capacities involved

\footnotetext{
22 This claim about existential analysis is of course wrong. Based on Heidegger's account of authenticity, Emmanuel Lévinas argues in his Totality and Infinity (1961) that human existence is fundamentally ethical, thus developing an alternative existentialist account of authenticity, which finds no sense in differentiating authenticity and ethics.
} 
in ethical decision-making plus the moral development necessary to exercise the moral component of authenticity. From that point of view, the moral component of authentic leadership is itself very complex and multileveled, because the interactions seasoned authentic leaders have gone through over time in order to develop a reliable moral conscience involve many factors. Algera and Lips-Wiersma have not provided good reasons for believing that their existential conception of human nature is better than the naturalistic conception (or any other philosophical conception). A first question we might ask is whether theirs is clearer. Then, can they provide at least some empirical evidence supporting specific aspects of their account-especially regarding efficiency? After all, leadership exists in relation to objectives. Leadership is, in other words, instrumental and if attaining objectives in efficient ways does not matter anymore, we have probably changed discourse somewhere along the way and are now talking about another topic. ${ }^{23}$

Despite this, there are three ideas central to the article by Algera \& Lips-Wiersma that I want to underline and fully endorse. First, they (2012, p. 120) criticize Walumbwa et al. (2008) for operationalizing authenticity in a way that neglects the complexity of the concept. Even though Walumbwa and Avolio (2014) conceded such criticisms, there are reasons to presume that they do not always fully consider all the psychological and philosophical aspects they initially sought to fuse into one theory. We have already argued above that this is the case for the moral component of authenticity, as they originally envisaged it. Nevertheless, empirical investigation has to make choices in order to yield results and if there are good arguments to design new experiments to investigate further, hitherto unexamined aspects of

\footnotetext{
23 There are also some serious general worries about taking a Heideggerian perspective. Since the publication of Heidegger's Black Notebooks, where he gives voice to his antisemitism and to fascist affinities, we cannot simply presume anymore, as Algera \& LipsWiersma did, that Heidegger's views on authenticity and ethical values have a special status, that they are somehow better or philosophically deeper than other views. Even if we are unwilling to simply ban Heidegger forever from all of our theorizing, what he has to say concerning authenticity and ethical values must be appraised very carefully. That work has just begun and there are still intricate questions to be asked concerning Heidegger's own authenticity, responsibility and ethics as a leader, especially when he was rector at Freiburg University, but also regarding his philosophical work (cf. Knowles 2019). Let me sharpen the philosophical problem, which comes with all this. From a logical point of view, the Heidegger case poses a paradox. The sometimes inauthentic Heidegger tells us that inauthenticity is inevitable. But, when saying that, is he being authentic or not? Framed like this, my objection is not simply an (illicit) ad hominem objection, but much more like the liar paradox applied to Heideggerian approaches to authentic leadership research. Without answers to these questions, I suggest, we better suspend utilizing passages from Heidegger's works as readily available building blocks for our theorizing about leadership and turn to something more reliable.
}

authenticity, Avolio and colleagues will probably be among the first to welcome such endeavors.

Second, Algera and Lips-Wiersma (op. cit., pp. 120-124) argue that because authentic leadership is tightly connected to positive organizational psychology, it does not usually investigate how inauthenticity arises. That is true and it is a problem. With a positive conception of human nature and a corresponding notion of moral conscience, authentic leadership theory has to have an account of how inauthentic - and especially unethical-leadership arises. We should, pace Algera and Lips-Wiersma, not presuppose without good further reasons that philosophy is in the best position to fully elucidate inauthenticity. As has been mentioned above, Bandura's account of moral disengagement can help us study many aspects of unethical leadership and, thus, allows us to better understand what authentic leadership does require. Furthermore, there is a vast literature on psychodynamic aspects of leadership, which does help us elucidate unethical leadership and other cases of dysfunctional behavior in organizations, which are not covered by Bandura's account. This need not amount to a rejection of a basic commitment to positive organizational psychology, but it might involve broadening the theoretical outlook in order to be better able to elucidate authentic leadership in its entirety.

Third, based on other research, Algera and Lips-Wiersma (pp. 127-128) argue that regarding responsibility we should consider organizations as a whole and ask what influence organizational culture has. For them, authentic leadership theory focuses too much on personal responsibility, even though we should also take collective responsibility into consideration. Going, again, back to the naturalistic account of moral conscience sketched above, this is of course true: much of the presentation given does focus on individual responsibility. Nevertheless, bearing in mind the role that empathy and perspective-taking play in the account, social interaction is pivotal and hence questions concerning the social dimension of moral conscience are not a change of topic or just an interesting excursus. ${ }^{24}$ And there is also a general point about good accounts of ethical leadership that must be added here: Leadership is not only about individual leaders, but also about followers and organizational structures. An account of ethical leadership must therefore deliver more than merely a list of criteria for identifying ethical leaders, it must also explain how ethical leadership affects followers and organizational structures. So, if the relation between authenticity and ethical leadership established here

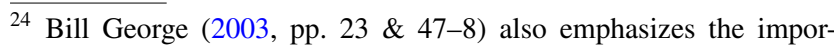
tance of the social dimension for authentic leadership practice: not only does authenticity involve a capacity to develop stable relationships, but it also involves acknowledging one's social responsibilities.
} 
is any good, it must also provide a sure footing for elucidating the social dimension.

Historically, proponents of moral conscience did not forget about the implications their accounts had for societies. In the next and final section, I shall draw on these sources to make a (preliminary) suggestion cocerning how the social dimension of ethical leadership can be elucidated by authentic leadership theory.

\section{The social dimension of moral conscience}

Moral conscience has been discussed by philosophers during the last 2500 years and the notion normally refers to a form of moral knowledge that is, in traditional terminology, "shared by oneself". ${ }^{25}$ This need not mean that the source of moral values cannot be external, but it does mean that selfknowledge does play an important role. According to the specific account introduced above, we hold onto the personal and subjective character of a specific self-knowledge, which is seen as a natural phenomenon and, at least in principle, a matter of empirical facts.

What is special about the account presented here is the role perspective-taking plays. Moral conscience has an emotional component (called empathy) and an intellectual component, which together allow us to use social interactions to develop more impartial views and to motivate us morally. Perspective-taking, together with other cognitive capacities constituting a sensitivity to interdependencies between facts at different times and different people (including their needs), is the basis for ethical decision-making. In other words, a sensitivity to social matters is build into this concept of moral conscience. But what can we deduce from this for organizational cultures or even society as a whole?

Traditionally, there are some lines of argument for the freedom of conscience, which explain the social role of conceptions of moral conscience such as the one proposed here. One first argument, which is often associated with Pierre Bayle (1686-1688) (2005) and John Locke's (2010) Second Letter Concerning Tolerance is the argument from humility. ${ }^{26}$ The argument is also called "argument from ignorance," because it is a skeptical approach to the content of conscience: it is always possible that what we consciously believe is wrong and that those with beliefs opposite to ours are right. This is the epistemological upshot from saying that the content of moral conscience is subjective and that

\footnotetext{
${ }^{25}$ See Sorabji 2014 for a detailed account.

${ }^{26}$ Sorabji (2014, p. 139) also mentions Richard Overton, William Walwyn, Milton, Hobbes and St.Augustine, which illustrates that a wide variety of writers thought about this possible implication of moral conscience.
}

perspective-taking is necessary in order to arrive at impartial beliefs about morality. From a social perspective, this is the basis for a requirement of tolerance (Sulmasy 2008, p. 144). There is a reason not to force anyone to do something or believe in things, which might turn out morally wrong. Applied to leadership, authentic leaders must not force followers to adopt particular moral values and should grant them a right of conscientious objection. And because authentic leadership is both part and parcel of an authentic organization — and, ideally, of an authentic society—such a right will be an important social convention, as it has a considerable impact on the form social interactions take within such a group of people.

Another important argument comes from John Stuart Mill (1859), who wrote in chapter 2 of his On Liberty:

Complete liberty of contradicting and disproving our opinion, is the very condition which justifies us in assuming its truth for purposes of action; and on no other terms can a being with human faculties have any rational assurance of being right.

This appears, at first glance, not to really address moral conscience. But in fact, it is about the role that subjective beliefs and values, those forming the content of moral conscience, must have in social interaction in order to institutionalize freedom of conscience for everybody and to foster progress as a group. Perspective-taking is much easier (and often even only possible) if subjective beliefs and values are disclosed openly. And if we disclose the contents of our moral conscience and find no opposition or alternative to that opinion, we can claim being impartial as much as it is possible in that situation. According to Mill, this is all the rational assurance we can get for being right in thought, talk and action.

Applied to leadership, Mill's argument compels authentic leaders to make sure that all interactions qualify as authentic too. Subjective beliefs and values are to be disclosed within the group in order to optimize conditions for perspectivetaking and, thereby, for rational decision-making processes which yield results that can rationally be claimed to be as impartial and ethically good as possible. This is not only a way of recognizing what everybody has to contribute, but it is also a way of recognizing under what conditions diverse views can interact to achieve objectives as a group.

The first argument is a principle of tolerance and the second argument is a principle of transparency. Both are necessary requirements for institutionalizing perspectivetaking in a group of people. For organizations and societies, they secure a culture in which perspective-taking is both demanded and also ensures moral growth as well as moral motivation. Leaders of groups violating these principles cannot count as authentic leaders. And groups which do not have these principles as social conventions are probably not 
the most conducive environments for the development of authentic leadership.

Note that both principles naturally flow from the conception of moral conscience. But they are in no way characteristics of individuals or reducible to such characteristics. Both principles only make sense as social institutions or conventions, governing the form interactions take within groups. In other words, the two principles describe properties of authentic interactions within groups. And such authentic interactions can possibly manifest within the group even if the leader does not have all the individual marks of authentic leadership that Avolio and colleagues associated with such an individual. Chances are, however, that an inauthentic leader within an authentic group will become authentic-first by playing along with others and later by conviction-or, else, the leader has to leave or the group will disband.

The point of looking at the social dimension of authentic leadership and of inferring the two principles for authentic interaction from our notion of moral conscience is this: authentic leadership has social characteristics, at least as far as ethical issues are concerned, which cannot be reduced to facts about the psychology of individual leaders. Authentic leadership theory has not conceptualized this clearly so far. But this is probably a dimension, which even those leadership scholars who basically agree with the perspective of Avolio and colleagues have to study more closely. The mantra that got us to this conclusion is: "Look more closely at perspective-taking." And in fact, it appears to be the prescription that allows us to understand not only moral development, the basic properties of moral conscience, and authenticity in individual leaders, but also what sorts of interaction within groups are important elements of authentic leadership. It might even be the key to authentic leadership per se.

\section{Concluding remarks}

The paper began with a remark by Peter Drucker on professional ethics for managers. For him, managers should above all do no harm. Upon closer inspection on the special ethical challenges that powerholders have to deal with, I followed Joane Ciulla and claimed that leadership theories must conceptualize good leadership as involving both efficiency and ethical goodness. After a few remarks on methods and the role philosophical analysis can play in leadership theories, I examined through a close reading a particular leadership theory, which claims to centrally involve ethical leadership, namely authentic leadership theory.

The main part of the paper consisted in a close reading of the two texts, which are commonly taken to explain how authenticity and ethical leadership are related: Schulman 2002 and May et al. 2003. The reading involved a few criticisms and expanding certain points. Central to the analysis was the development of a notion of moral conscience, which has empathy and perspective-taking as its most central elements. The claim was that a proper understanding of moral conscience explains how authenticity and ethical leadership are related.

Once the basic building-blocks of the relation between authenticity and ethical leadership were available, three objections from the literature were examined and rejected. Not all objections, however, were fully dismissed, because the criticism that authentic leadership theory is much to individualistic was found to raise an important challenge. After all, leadership involves followers and organizational structures too. Therefore, any good account of ethical leadership must spell out the social dimension, how ethics affects followers and organizations. This let me to develop two principles for authentic interaction, which-as I argued-flow from the notion of moral conscience, which relates authenticity and ethical leadership.

Going back to Drucker's take on ethical leadership, we can still agree that leaders should do no harm. But, if my arguments are right, we should hasten to add that they need moral conscience to do that. This is an important point that lies right below the surface of some of the earlier academic writings on authentic leadership. Unearthing and reexamining it gives us a detailed and complete picture of ethical leadership. There is, of course, much need for examining the claims empirically. But that sort of work is easier if the general direction, the conceptual framework we may employ in the field, is clear.

Open Access This article is licensed under a Creative Commons Attribution 4.0 International License, which permits use, sharing, adaptation, distribution and reproduction in any medium or format, as long as you give appropriate credit to the original author(s) and the source, provide a link to the Creative Commons licence, and indicate if changes were made. The images or other third party material in this article are included in the article's Creative Commons licence, unless indicated otherwise in a credit line to the material. If material is not included in the article's Creative Commons licence and your intended use is not permitted by statutory regulation or exceeds the permitted use, you will need to obtain permission directly from the copyright holder. To view a copy of this licence, visit http://creativecommons.org/licenses/by/4.0/.

\section{References}

Algera PM, Lips-Wiersma M (2012) Radical authentic leadership: cocreating the conditions under which all members of the organization can be authentic. Leadersh Q 23:118-131

Anderson C, Galinsky AD (2006) Power, optimism, and risk-taking. Euro J Soc Psychol 36(4):511-536

Avolio BJ, Gardner WL (2005) Authentic leadership development: Getting to the root of positive forms of leadership. Leadersh Q 16:315-338

Avolio BJ, Walumbwa FO (2014) Authentic leadership theory, research and practice: steps taken and steps that remain. In: Day D (ed) The Oxford handbook of Leadership and Organizations, OUP, Oxford, pp 331-356. 
Bandura A (2016) Moral Disengagement. Worth Publishers How People Do Harm And Live With Themselves, New York

Bayle P 1686-1688 (2005) Philosophical commentary on these words of Jesus Christ "compel them to come in, that my house may be full". In: J Kilcullen, Kukhatas CH (eds) Liberty Fund, Indianapolis.

Bennis WG, Thomas RJ (2002) Geeks \& geezers: how era, values, and defining moments shape leaders. Harvard Business School Press, Boston

Blader SL, Chen Y-R (2012) Differentiating the effects of status and power: a justice perspective. J Pers Soc Psychol 36:497-509

Caza A, Jackson B (2011) Authentic Leadership. In: Bryman A, et al. (eds) The SAGE Handbook of Leadership. SAGE, Los Angeles, pp 352-s364

Chen S, Lee-Chai AY, Bargh JA (2001) Relationship orientation as moderator of the effects of social power. J Pers Soc Psychol 80:183-187

Ciulla JB (2017) Ethics and effectiveness: the nature of good leadership. In: Antonakis J, Day D (eds) The Nature of Leadership, 3rd edn. SAGE, Los Angeles, pp 438-468

Ciulla JB (2013) Searching for mandela: the saint as a sinner who keeps on trying. In: Ladkin D, Spiller C (eds) Authentic leadership. Clashes, convergences and coalescences. Edward Elgar, Cheltenham, pp 152-175

Ciulla JB, Forsyth DR (2011) Leadership Ethics. In: Bryman A, et al. (eds) The SAGE Handbook of Leadership. SAGE, Los Angeles, pp 229-241

DeCelles KA, DeRue DS, Margolis JD, Ceranic TL (2012) Does power corrupt or enable? When and why power facilitates self-interested behavior. J Appl Psychol 97:681-689

Drucker PF (2008) Management, Revised edn. Harper Collins, New York

Galinsky AD, Magee JC, Gruenfeld DH, Whitson JA, Liljenquist KA (2008) Power reduces the press of the situation: Implications for creativity, conformity, and dissonance. J Pers Soc Psychol 95:1450-1466

Gardner WL, Avolio BJ, Luthans F, May DR, Walumbwa F (2005a) 'Can you see the real me?' A self-based model of authentic leader and follower development. Leadersh Q 16:343-372

Gardner WL, Avolio BJ, Walumbwa FO (2005b) Authentic leadership development: emergent trends and future directions. In: Gardner WL, Avolio BJ, Walumbwa FO (eds) Authentic leadership theory and practice: Origins, effects, and development. Elsevier Science, Oxford, pp 387-406

George B (2003) Authentic Leadership. Rediscovering the secrets to creating lasting values. Jossey-Bass, San Francisco

Greene J (2013) Moral tribes Emotion, reason, and the gap between Us and them. Penguin, New York

Guignon CB, Pereboom D (1995) Existentialism: Basic writings. Hackett, Indianapolis
Kets de Vries M, Balazs K (2011) The shadow side of leadership. In: Bryman A, et al. (eds) The SAGE handbook of leadership. SAGE, Los Angeles, pp 380-392

Knowles A (2019) Heidegger's fascist affinities. a politics of silence. Stanford University Press, Stanford

Ladkin D, Spiller CH, Craze G (2016) The journey of individuation: a Jungian alternative to the theory and practice of leading authentically. Leadership. https://doi.org/10.1177/1742715016681942

Lévinas E (1961) Totalité et Infini: Essais sur l'Extériorité, Phaenomenologica 8. Martinus Nijhoff, The Hague

Locke J 1690 (2010) A Second Letter Concerning Toleration. In: Vernon $\mathrm{R}$ (ed) Locke on Toleration. CUP, Cambridge, pp 67-107

Luthans F (2002) Positive organizational behavior: developing and managing psychological strengths. Acad Manag Exec 16(1):57-72

Luthans F, Avolio B (2003) Authentic Leadership Development. In: Cameron KS, Dutton JE, Quinn RE (eds) Positive organizational scholarship: foundations of a new discipline. Berrett-Koehler Publishers, San Francisco, pp 241-258

May DR, Chan AYL, Hodges TD, Avolio BJ (2003) Developing the moral component of authentic leadership. Organ Dyn 32:247-260

Mill JS (1859) On Liberty; https://ebooks.adelaide.edu.au/m/mill/john_ stuart $/ \mathrm{m} 645 \mathrm{o} /$. Accessed 02 Apr 2019.

Northouse PG (2016) Leadership. theory and practice, 7th edn. SAGE Publications, Thousand Oaks

Parfit D (2011) On What Matters (Vol 1). OUP, Oxford

Plato (1992) Republic Grube, GMA (trans) Hackett Indianapolis

Schulman M (2002) How we become moral: the sources of moral motivation. In: Snyder CR, Lopez SJ (eds) Handbook of positive psychology. OUP, Oxford, pp 499-512

Seligman MEP, Csikszentmihalyi M (2000) Positive psychology: an introduction. Am Psychol 53(1):5-14

Shamir B, Eilam G (2005) 'What's your story?' A life-stories approach to authentic leadership development. Leadersh Q 16:395-417

Sorabji R (2014) Moral conscience through the ages. OUP, Oxford

Sulmasy DP (2008) What is conscience and why is respect for it so important. Theor Med Bioeth 29(3):135-149

Van Kleef GA, Oveis C, Homan A, van der Löwe I, Keltner D (2015) Power gets you high: the powerful are more inspired by themselves than by others. Soc Psychol Personal Sci 6:472-480

Van Kleef GA, Oveis C, van der Löwe I, LuoKogan A, Goetz J, Keltner D (2008) Power, distress, and compassion: turning a blind eye to the suffering of others. Psychol Sci 19:1315-1322

Walumbwa FO, Avolio BJ, Gardner WL, Wernsing TS, Peterson SJ (2008) Authentic leadership: development and validation of a theory-based measure. J Manag 34(1):89-126 